\title{
Determinants of physical activity in primary school students using the health belief model
}

\author{
This article was published in the following Dove Press journal: \\ Journal of Multidisciplinary Healthcare \\ 20 March 2013 \\ Number of times this article has been viewed
}

\author{
Sireewat Ar-yuwat ${ }^{1,2}$ \\ Mary Jo Clark ${ }^{2}$ \\ Anita Hunter ${ }^{3}$ \\ Kathy S James ${ }^{2}$
}

'Boromarajonani College of Nursing Nakhon Lampang (BCNLP), Lampang, Thailand; ${ }^{2} \mathrm{Hahn}$ School of Nursing and Health Science, University of San Diego, San Diego, CA, ${ }^{3}$ Department of Nursing, Dominican University of California, San Rafael, CA, USA
Correspondence: Sireewat Ar-yuwat Boromarajonani College of Nursing Nakhon Lampang (BCNLP),

268, Parkam Road, Tambol Hauwieng,

Muang District, Lampang, 52000,

Thailand

Tel +6654226254

Fax +66 54225020

Email sireewat@yahoo.com
Background: Thailand is a middle-income country in which two-thirds of children demonstrate an insufficient level of physical activity. Physical inactivity is a major risk factor for obesity and many other health-related consequences in children. Thus, it is important to understand how primary school children perceive things in their daily life as determinants of physical activity. The purpose of this study was to investigate the impact of cues, perceived benefits, and perceived barriers on the level of physical activity among primary school students.

Methods: A cross-sectional study was conducted in Phitsanulok Province, Thailand, in 2011. Multistage sampling selected a total of 123 primary school students. The Physical Activity Questionnaire for Older Children and the Cues, Perceived Benefits, and Barriers to Physical Activity Questionnaire were used to assess the student levels of physical activity, as well as the perceived benefits, barriers, and cues to action. The association between these factors and the level of physical activity was determined by correlation statistics and confirmed by robust regression. Multivariate analysis of variance compared health belief model determinants: perceived benefits, perceived barriers, and cues to action on physical activity between male and female students. Self-administered questionnaires were validated and tested in a pilot study.

Results: The level of activity among primary school children was significantly influenced by perceived barriers, such as fear of strangers when playing outdoors, bad weather, and too much homework. However, activity was not influenced by cues to action or perceived benefits. Perceived benefits, barriers, and cues to physical activity did not differ by gender.

Conclusion: A safe environment and fewer barriers, such as amount of homework, could enhance physical activity in primary school children.

Keywords: physical activity, health belief model, primary school students, children, physical activity

\section{Introduction}

Children are naturally playful. However, recent surveys of children's health in 2008 and 2009 indicated that only $33.7 \%$ of Thai children aged 10-14 years did sufficient physical activity, ie, 60 minutes at least five times per week. Almost $60 \%$ of the children watched television more than 3 hours per day during weekends. The rate of physical inactivity in children from Phitsanulok Province was the second highest in Northern Thailand. ${ }^{1}$ Moreover, almost nine in ten children (86.0\%) traveled to school by car, and only one in ten children spent more than 3 hours per day playing outdoors. ${ }^{2}$ Similarly, in the urban Phitsanulok Province, attending after school tutorial programs rather than engaging in physical activity classes was linked with overweight and obesity, ${ }^{3}$ which are major health problems among primary school children in Thailand. ${ }^{4}$ According to a 
retrospective study of primary school students from three Thai provinces, the prevalence of obesity increased dramatically during a 6-year follow-up period. In the Bangkok, Saraburi, and Sakolnakhon provinces, rates of obesity in grade 1 students were $16 \%, 23 \%$, and $4 \%$, respectively, and increased to $31 \%, 30 \%$, and $9 \%$, respectively, in Grade 6 students. ${ }^{5}$

Several studies have addressed both eating behavior and physical activity as factors contributing to childhood obesity. Many studies of physical activity have reported that children have become less physically active than in previous years. However, only one study in Thailand obtained data for obese children, examining the perceived benefits of and barriers to physical activity. ${ }^{6-10}$

Although physical inactivity has been identified by many etiological studies as a cause of childhood obesity, there is limited literature on the factors influencing physical inactivity, particularly among primary school children. It is still unclear what the perceived benefits, barriers, and cues to physical activity are and whether these factors relate to the level of physical activity.

The need to understand and address perceived benefits, barriers, and cues to physical activity specifically among children cannot be overlooked. Therefore, a quantitative study using the health belief model as a theoretical framework was conducted to examine associations between these variables. The results of this study should inform different audiences, including politicians, policy makers, health educators, administrators, and teachers, in order to develop effective obesity prevention programs. Moreover, parents or parent organizations will be able to understand these issues better, so as to cooperate with and support prevention programs.

The purpose of this study was to investigate whether cues to action, perceived benefits, and perceived barriers were related to physical activity levels in primary school students. The specific aims of the study were to examine the relationships between the perceived benefits, perceived barriers, and cues to action and levels of physical activity among primary school students, and to compare the effects of the perceived benefits, perceived barriers, and cues to action on physical activity between male and female students.

\section{Materials and methods Study design and setting}

This was a cross-sectional, descriptive study based on the theoretical framework of the health belief model. The dependent variable was the level of physical activity of Grade 4 primary school students. Their gender, and perceived benefits, perceived barriers, and cues to action were the independent variables of interest. The study was conducted in three primary schools in Muang district, Phitsanulok Province, northern Thailand from October 2010 to March 2011, and was approved by the institutional review board of the University of San Diego, San Diego, CA, USA. The investigator obtained permission from the participant schools, informed parental consent, and student assent prior to study enrolment.

Altogether, there were 2244 Grade 4 primary school students at 16 primary schools in Muang district. Those primary schools received funding from one of three sources, ie, Ministry of the Interior, Ministry of Education, or private education organizations. The socioeconomic status of students' families differed among the three types of schools, so participating schools were recruited from each category.

\section{Sample size and selection}

Multistage sampling selected Grade 4 primary school students during the 2011 academic year. Children aged 9 years and older were considered mature enough for the reasoning, thinking, and problem-solving needed to answer the self-administered questionnaires. ${ }^{11,12}$ First, stratified random sampling was applied to choose one school from each funding category. Second, simple random sampling identified one Grade 4 class from each school. All students in the selected classes were then invited to participate in the study. The effect size was set for a medium effect based on a statistical significance level of 0.05 and an estimated power of 0.80 . The total number of participants needed for this study was $85 .{ }^{13}$ To compensate for nonresponses, the sample size was increased by $15 \%$, bringing the total anticipated number of subjects to 98 students, an average of 33 from each school.

\section{Measurement of study outcome and determinants}

Two instruments were used to assess the variables of interest. These variables included physical activity levels and selected determinants of activity.

\section{Physical activity}

Physical activity measures included the types and frequency of physical activity performed by the Grade 4 students over the previous 7 days. Physical activity during the student's spare time was defined as activity that caused the student to sweat, to breathe hard, or to make their legs feel tired.

The Physical Activity Questionnaire for Older Children was used to measure levels of physical activity. ${ }^{14}$ This instrument is a self-administered survey used to assess general moderate to vigorous physical activity levels over the 
previous 7 days. The questionnaire is designed for students in Grades 4-8, aged 8-14 years. Some questions from this public domain questionnaire were adapted in this study so as to be suitable for Thai students. The revised instrument consisted of ten items. Demographic questions dealt with gender and the name of the school. The first item examined spare time activities from the past week on a five-point scale ( $1=$ no activity, $5=$ seven times or more). Items $2-8$ examined the type and frequency of activities during physical education class, recess, lunch, after school, evenings, and weekends. The response choices for these items ranged from 1 (the lowest activity response) to 5 (the highest activity response). Item 9 examined the frequency of physical activity for each day of the previous week $(1=$ none, $5=$ very often $)$. The last item examined illness and obstacles that made students unable to engage in their usual physical activity during the previous week. The final score was calculated as the mean of items 1 to 9 , with a possible score ranging from 1 to 5 , with a score of 1 indicating low physical activity and a score of 5 indicating a high level of physical activity. The reliability coefficient for this questionnaire in our study was 0.911 .

\section{Determinants of health belief model}

The health belief model was used to explain how the perceptions of students influence their behavior relating to engagement in physical activity. The health belief model posits that beliefs about health and health-related practices are influenced by several factors, including the perceived seriousness of a health condition, one's own perceived susceptibility to the condition, and perceptions of the benefits of and barriers to action to prevent the condition. An additional element of the model is cues to action, ie, circumstances in one's environment that might stimulate action. Because this study was concerned with the performance or nonperformance of an action to promote health, rather than on perceptions of severity or vulnerability to a particular condition, it focused on children's perceptions of the benefits of physical activity, barriers to engaging in physical activity, and cues to action that would promote activity.

Perceived benefits of physical activity are defined as the positive reasons the children had for exercising or for considering exercising. Perceived barriers are defined as the reasons the children had for not exercising or for not considering exercising. Cues to action are defined as the factors that help or would help children to exercise. Modifying these factors, health belief model determinants could increase the physical activity of children. The Cues, Perceived Benefits and Barriers to Physical Activity Questionnaire was used to examine these variables in primary school students. This questionnaire was based on an instrument used by Tergerson and King ${ }^{9}$ with adaptations based on findings from previous studies in Thailand. The questions were created to address three components of the health belief model. A subscale of the Cues, Perceived Benefits and Barriers to Physical Activity Questionnaire measured each of the three variables of interest. The perceived benefits and perceived barriers subscales each consisted of 17 items, and the cues to action subscale consisted of 13 items. The responses to all subscale items were made on a four-point scale, with 1 indicating strong disagreement with the statement and 4 indicating strong agreement. The means of the students' responses to items on each subscale were used to interpret the data, with higher mean scores reflecting greater beliefs. The reliability coefficients for the perceived benefits, perceived barriers, and cues to action subscales were $0.847,0.837$, and 0.915 , respectively.

\section{Statistical analysis}

The characteristics of the sample were described using means, standard deviations, frequencies, and percentages. Pearson's correlation coefficient, Spearman's rho, and robust regression were used to analyze the relationship between the independent variables and the dependent variable of physical activity. The level for statistical significance was set at 0.05 . Moreover, differences in the perceived benefits, barriers, and cues to action between boys and girls were analyzed by multivariate analysis of variance. The data were analyzed using the Statistical Package for the Social Sciences/Personal Computer version 11.5 (SPSS Inc, Chicago, IL) and Stata SE version 11 (Stata Corporation, College Station, TX).

\section{Results}

The study findings are presented in terms of participant characteristics, levels of physical activity, and the relationship between perceived barriers, benefits, and cues to action subscale scores and physical activity levels. Differences by gender are also presented.

\section{Participant characteristics}

A total of 123 Grade 4 primary school students participated in the study. The sample included 60 boys and 63 girls, ranging in age from 9 to 11 years. The types of schools were fairly evenly represented. The majority of participants had either friends or parents who exercised, and most students reported their parents encouraged them to exercise. About $60 \%$ of the participants were trying to lose weight, but only about a third were members of sports teams. More than half took extra 
Table I Demographic characteristics of participants and physical activity descriptors $(n=123)$

\begin{tabular}{|c|c|c|c|}
\hline $\begin{array}{l}\text { Participant } \\
\text { characteristics }\end{array}$ & Category & $\begin{array}{l}\text { Frequency } \\
\text { n (\%) }\end{array}$ & $\overline{\mathbf{x}} \pm$ SD \\
\hline \multirow[t]{4}{*}{ Age (years) } & 9 & $20(16.4 \%)$ & $9.87 \pm 0.42$ \\
\hline & 10 & 98 (80.3\%) & \\
\hline & II & $4(3.3 \%)$ & \\
\hline & Missing & I & \\
\hline \multirow[t]{3}{*}{ Gender } & Male & $60(49.2 \%)$ & \\
\hline & Female & $62(50.8 \%)$ & \\
\hline & Missing & I & \\
\hline \multirow[t]{3}{*}{ School } & $\begin{array}{l}\text { Ministry } \\
\text { of the interior }\end{array}$ & $36(29.3 \%)$ & \\
\hline & $\begin{array}{l}\text { Ministry } \\
\text { of education }\end{array}$ & $42(34.1 \%)$ & \\
\hline & Private & 45 (36.6\%) & \\
\hline Do you have a friend & Yes & 98 (79.7\%) & \\
\hline who exercises? & No & $25(20.3 \%)$ & \\
\hline Do you have a parent & Yes & $105(85.4 \%)$ & \\
\hline who exercises? & No & $18(14.6 \%)$ & \\
\hline Do you have a parent & Yes & 98 (79.7\%) & \\
\hline $\begin{array}{l}\text { who encourages you } \\
\text { to exercise? }\end{array}$ & No & 25 (20.3\%) & \\
\hline Are you currently & Yes & $76(61.8 \%)$ & \\
\hline trying to lose weight? & No & 47 (38.2\%) & \\
\hline Are you a member & Yes & 40 (32.5\%) & \\
\hline $\begin{array}{l}\text { of any kind of sports } \\
\text { team? }\end{array}$ & No & $83(67.5 \%)$ & \\
\hline Do you take extra & Yes & $63(51.2 \%)$ & \\
\hline classes? & No & $60(48.8 \%)$ & \\
\hline Were you sick last & Yes & $25(20.3 \%)$ & \\
\hline week? & No & 98 (79.7\%) & \\
\hline
\end{tabular}

classes. During the week before data collection, most of the participants were free from major illness (Table 1).

\section{Level of physical activity}

The study sample had a moderate level of physical activity, with a mean activity level of $3.3 \pm 0.5$. Boys engaged in physical activity more often than girls, with mean physical activity scores of 3.4 and 3.2, respectively (see Figure 1). Cycling was the favorite type of physical activity among boys, followed by skipping and soccer. Use of a hula hoop was most often reported by girls, followed by cycling and skipping. Among the three independent variables, only the perceived barriers variable had a significant inverse relationship with the level of physical activity. The perceived benefits variable was significantly related to the cues to action variable, but neither variable was significantly related to physical activity (Table 2). Pearson and Spearman's rho correlations identified no variable to be significantly correlated with the level of physical activity among boys. Similar to the results for the total sample, the perceived benefits variable was significantly

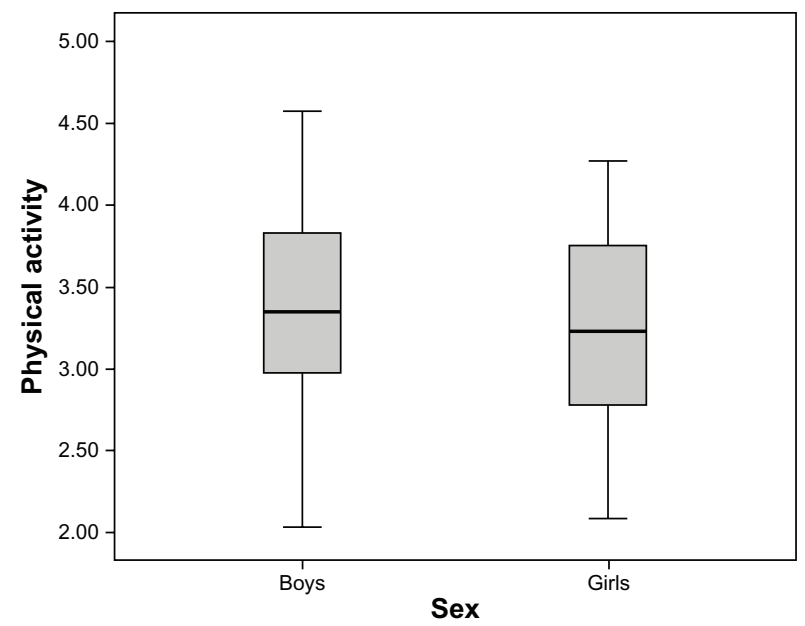

Figure I Average physical activity levels of primary school students in the week before data collection.

related to the cues to action variable (Table 3). For girls, perceived barriers had an inverse relationship with levels of physical activity. Like the boys, the perceived benefits variable was also significantly related to the cues to action variable (Table 4).

As indicated in Table 5, regression analysis adjusted for gender indicated that, of the three health belief model variables, only the perceived barriers variable was significantly and inversely associated with the level of physical activity. The graphic regression in Figure 2 showed that perceived barriers of the children negatively predicted their physical activity (Figure 2).

Multivariate analysis of variance showed that the mean scores for perceived benefits, perceived barriers, and cues to action did not differ significantly between boys and girls (Table 6). The top three perceived benefits of physical activity were the same for both boys and girls, ie, "to be healthy", "to become strong", and "to make me happy." Boys perceived more barriers to physical activity than girls. The greatest perceived barriers to physical activity for boys included fear of strangers, bad weather, and being tired. For girls, the top three perceived barriers to physical activity were too much

Table 2 Correlation coefficients for variables related to physical activity

\begin{tabular}{lllll}
\hline Variables & $\begin{array}{l}\text { Physical } \\
\text { activity }\end{array}$ & $\begin{array}{l}\text { Perceived } \\
\text { benefits }\end{array}$ & $\begin{array}{l}\text { Perceived } \\
\text { barriers }\end{array}$ & $\begin{array}{l}\text { Cues to } \\
\text { action }\end{array}$ \\
\hline Physical activity & $\mathrm{I}$ & 0.082 & $-0.197^{*}$ & 0.092 \\
Perceived benefits & & $\mathrm{I}$ & -0.152 & $0.507^{* *}$ \\
Perceived barriers & & & $\mathrm{I}$ & -0.099 \\
Cues to action & & & & $\mathrm{I}$ \\
\hline
\end{tabular}

Notes: *Correlation is significant at the 0.05 level (two-tailed); **correlation is significant at the 0.01 level (two-tailed). 
Table 3 Correlation coefficients for variables related to physical activity in boys

\begin{tabular}{lllll}
\hline Variables & $\begin{array}{l}\text { Physical } \\
\text { activity }\end{array}$ & $\begin{array}{l}\text { Perceived } \\
\text { benefits }\end{array}$ & $\begin{array}{l}\text { Perceived } \\
\text { barriers }\end{array}$ & $\begin{array}{l}\text { Cues to } \\
\text { action }\end{array}$ \\
\hline Physical activity & $\mathrm{I}$ & 0.093 & -0.220 & 0.038 \\
Perceived benefits & & $\mathrm{I}$ & -0.215 & $0.590 * *$ \\
Perceived barriers & & & $\mathrm{I}$ & -0.216 \\
Cues to action & & & & $\mathrm{I}$ \\
\hline
\end{tabular}

Note: $* *$ Correlation is significant at the 0.01 level (two-tailed).

homework, bad weather, and fear of strangers. Girls perceived more cues to physical activity than boys.

Boys and girls had similar cues to action. Being told that physical activity is good for health was the most frequently perceived cue to action. Having a sports field or a space to play and parental encouragement to exercise were the second and third most frequently reported cues to physical activity among boys. The second and third ranked cues among girls were parental support in taking them to a place to play and parental encouragement.

\section{Discussion}

While both quantitative and qualitative studies have explored factors influencing physical activity, studies examining the relationship between those factors and levels of physical activity have been limited. In addition, most studies overlooked some important variables, particularly children's perceptions of factors influencing their levels of physical activity, such as perceived benefits, perceived barriers, and cues to physical activity. The present study investigated the role of cues to action, perceived benefits, and perceived barriers in promoting physical activity in Grade 4 students in the primary school setting in Phitsanulok Province, Thailand.

The Grade 4 students in this study were aged 9-11 years, so were mature enough to respond to the questionnaires. ${ }^{12}$ The finding of a moderate level of physical activity in this study is consistent with those of Sanamthong ${ }^{15}$ who reported that obese children were engaged in less physical activity than recommended by current guidelines. Although the present

Table 4 Correlation coefficients for variables related to physical activity in girls

\begin{tabular}{lllll}
\hline Variables & $\begin{array}{l}\text { Physical } \\
\text { activity }\end{array}$ & $\begin{array}{l}\text { Perceived } \\
\text { benefits }\end{array}$ & $\begin{array}{l}\text { Perceived } \\
\text { barriers }\end{array}$ & $\begin{array}{l}\text { Cues to } \\
\text { action }\end{array}$ \\
\hline Physical activity & $\mathrm{I}$ & 0.066 & $-0.212 *$ & 0.051 \\
Perceived benefits & & $\mathrm{I}$ & -0.096 & $0.421 * *$ \\
Perceived barriers & & & $\mathrm{I}$ & 0.014 \\
Cues to action & & & & $\mathrm{I}$ \\
\hline
\end{tabular}

Notes: *Correlation is significant at the 0.05 level (two-tailed); **correlation is significant at the 0.01 level (two-tailed).
Table 5 Robust regression for variables related to physical activity

\begin{tabular}{llllll}
\hline Variables & Coeff & SE & $\boldsymbol{P}$ & $\mathbf{9 5 \%} \mathbf{C l}$ & \\
\hline Constant & 3.865 & 0.619 & 0.000 & 2.638 & 5.093 \\
Gender & $-0.15 \mathrm{I}$ & 0.109 & 0.169 & -0.368 & 0.065 \\
Perceived benefits & 0.056 & 0.168 & 0.738 & -0.277 & 0.389 \\
Perceived barriers & -0.272 & 0.126 & 0.033 & -0.522 & -0.022 \\
Cues to action & 0.008 & 0.134 & 0.952 & -0.258 & 0.274 \\
\hline
\end{tabular}

Abbreviations: Coeff, coefficient of variation; SE, standard error of the mean; $\mathrm{Cl}$, confidence interval.

study did not measure minutes of physical activity, as did Sanamthong, it demonstrated moderate activity, approximately 3-4 times a week.

Most of the participating children in this study perceived that physical activity would bring benefits such as good health, strength, happiness, feeling fresh, and better resistance to illness. These findings are consistent with several previous studies. In the northeastern part of Thailand, children mentioned benefits of exercise including losing weight, being healthy, and having fun. ${ }^{15}$ In the United States, sixth grade boys aged 11-13 years in the Midwest indicated their perceived benefits of physical activity as making them healthy, strong, and fit and allowing them to maintain an average weight. ${ }^{16}$

Children in the current study perceived a moderate level of barriers to physical activity, such as worry about strangers when playing outside, bad weather, too much homework, having discomfort after exercise, and being too tired for physical activity. Conversely, Wannasuntad ${ }^{17}$ reported that students in Bangkok perceived few barriers to participating in physical activity. However, the present study supports the findings of other investigations. Barriers to physical activity identified for boys in prior studies included

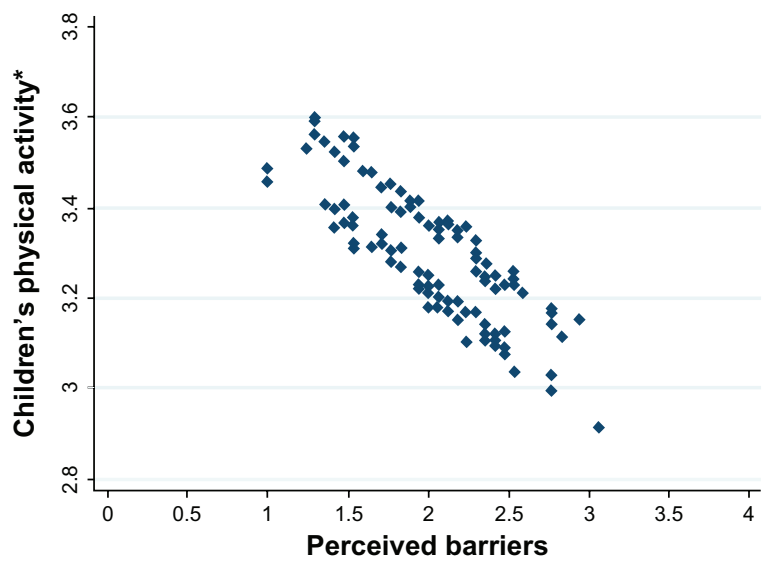

Figure 2 Associtaion between perceived barriers and primary school student's physical activity predicted by robust regression, Phitsanulok, Thailand, 2010.

Note: $* Y$ axis showed robust regression predicted physical activity of primary school students. 
Table 6 Multivariate analysis of variance of gender differences in perceived benefits, perceived barriers, and cues to action scores

\begin{tabular}{llllllll}
\hline $\begin{array}{l}\text { HBM } \\
\text { determinants }\end{array}$ & Gender & n & Mean & SD & $\begin{array}{l}\text { Wilks' } \\
\text { lambda }\end{array}$ & F & P \\
\hline Perceived & Boys & 58 & 54.397 & 6.673 & 0.987 & 0.48 & 0.698 \\
benefits & Girls & 62 & 54.177 & 6.250 & & & \\
Perceived & Boys & 60 & 34.433 & 7.716 & & & \\
barriers & Girls & 62 & 34.194 & 7.335 & & & \\
Cues to action & Boys & 60 & 40.733 & 6.433 & & & \\
& Girls & 63 & 41.730 & 5.686 & & & \\
\hline
\end{tabular}

Abbreviations: HBM, health belief model; SD, standard deviation.

homework, watching television or playing computer games; girls mentioned other barriers, such as conflicts with social commitments, inactive parents, being overweight, or lack of fitness. ${ }^{18}$

The participants reported a number of cues that could motivate physical activity, including: being told that physical activity is good for their health; being taken by parents to play sports or exercise; having a sports field or free space nearby; and being encouraged to exercise by parents. Similar findings were noted by Heitzler et al among children and adolescents aged 10-17 years. ${ }^{19}$ Participants with higher levels of perceived support from their parents and friends reported higher levels of self-efficacy and enjoyment related to physical activity, and lower levels of perceived barriers.

Regarding the first study objective, only the perceived barriers variable had a significant inverse relationship with level of physical activity. Our study did not demonstrate the relationship between participant characteristics and level of physical activity found in other studies. Wannasuntad ${ }^{17}$ reported that $31 \%$ of the variance in physical activity was explained by gender, body mass index, number of hours watching television, number of hours playing outside, sibling or other child support, parental permission to play outside, extent of physical activity items or equipment available at home, school policy promoting physical activity, and children's self-efficacy in overcoming general barriers.

Boys in this study were found to be slightly more active than girls. However, the difference in physical activity level between boys and girls was not statistically significant. This finding is congruent with several other studies in both developed settings, such as Australia, the United Kingdom, and rural and urban regions of the United States, and developing settings such as Turkey and Thailand. . $^{1720-26}$

Moreover, perceived benefits, perceived barriers, and cues to action did not differ significantly between boys and girls. In the subgroup analysis, perceived barriers were significantly correlated with the level of physical activity in girls but not in boys. Boys seemed to be active despite perceived barriers. Previous studies around the world have reported a variety of different results in terms of gender differences in physical activity and its determinants. A study of middle school students in Midwestern United States found significantly different perceived benefits of physical activity between boys and girls. Girls had higher perceived benefits than boys on items such as "take care of myself", "stay in shape", and "be healthier". ${ }^{24}$ A qualitative study of sixth grade students in Winnipeg found that boys mentioned barriers to physical activity, including homework and screen time, but girls did not. ${ }^{18}$ Heitzler reported that girls aged $10-17$ years in the metropolitan Minnesota Twin Cities area mentioned more barriers to physical activity than boys, whereas no differences were found in a study of middle school students in the rural Midwest. ${ }^{23,24}$ The current study provides evidence, applicable to both boys and girls, of engagement in physical activity by children living in Thailand's urban settings. The more barriers to engaging in physical activity children perceive, the less they will play (Figure 2).

\section{Limitations}

This study examined three major elements of the health belief model, ie, perceived benefits, perceived barriers, and cues to action. These determinants helped the investigator to determine why the students did or did not participate in physical activity. Nevertheless, it is possible that there are more important factors influencing physical activity that should be identified. Future studies should consider other factors that can influence levels of physical activity, such as friends, family, environment, school policy, or the other components of the health belief model. Moreover, it is difficult to eliminate recall bias created by the 7-day recall of physical activity on the Physical Activity Questionnaire for Older Children. Children may have difficulty remembering all of the activities from the previous week. Future studies might effectively employ activity logs.

\section{Recommendations}

The current study findings have practical implications for nurses in developing health promotion programs that can help students overcome barriers to physical activity. Moreover, parents and teachers should cooperate with nurses to find strategies to achieve this goal. Health communication programs are essential for tailoring messages that promote physical activity and reduce the barriers perceived within specific groups. 
In addition, the present study showed differences in preferred activities between boys and girls. School nurses can cooperate with physical education teachers to develop interventions to promote physical activity specific to particular target groups, such as an exercise program requiring less equipment for girls. On the other hand, an exercise program for boys might emphasize sports or activities that need physical activity equipment. Nurses can be advocates for school policy and for sufficient physical activity within the school curriculum, such as expanding specific time dedicated to play. Creating safe and favorable environments and reducing homework may also help to promote physical activity among students and ultimately lead to a reduction of childhood obesity and prevention of life-style related diseases in Thailand.

\section{Conclusion}

The current study provided an overview of children's perceptions of determinants of physical activity and insight into gender differences in those perceptions and their impact. The physical activity level among primary school girls in urban Thailand was slightly lower than that of boys. Overall, perceived barriers hindered the physical activity of primary school children (Figure 2, Table 5). Importantly, the negative impact of perceived barriers on physical activity was significant among girls. Child health and school health interventions, focusing on eliminating or minimizing barriers, may lead to a sufficient level of physical activity among Thai primary school children.

\section{Acknowledgments}

The principals, teachers, students and parents from the primary schools involved are acknowledged for their kindness and willing participation in the study. Dr Myo Nyein Aung, Research Department, Boromarajonani College of Nursing Nakhon Lampang (BCNLP) was acknowledged for his important suggestions to the author for responding to the peer-review comments, and making regression graphics.

\section{Disclosure}

The authors report no conflicts of interest in this work.

\section{References}

1. Eakpalakorn W. The fourth survey of children's health from 2008-2009. Available from: http://www.nheso.or.th/loadfile/child_NHESO4\%20(1). pdf. Accessed October 17, 2012.

2. Usman Y. Factors related to obesity in primary school children: a case study of Nakhon Pathom Province, Thailand. Nakhon Pathom, Thailand: Mahidol University; 2004.
3. Thingchin O. Selected Factors Related to Overweight Level Among Overweight Elementary School Children, Grade 4-6, Urban Area, Phitsanulok Province. Phitsanulok, Thailand: Naresuan University; 2009.

4. Aekplakorn W, Mo-suwan L. Prevalence of obesity in Thailand. Obes Rev. 2009;10(6):589-592.

5. Jirapinyo P, Densupsoontorn N, Kongtragoolpitak S, Wong-Arn R, Thamonsiri N. Increasing risks of becoming obese after 6 years in primary school: comparing the relative risks among some schools in Bangkok, Saraburi and Sakolnakorn. J Med Assoc Thai. 2005;88(6): 829-832.

6. de Vries SI, Bakker I, van Mechelen W, Hopman-Rock M. Determinants of activity-friendly neighborhoods for children: results from the SPACE study. Am J Health Promot. 2007;21(Suppl 4):312-316.

7. Lee PH, Lai HR, Chou YH, Chang LI, Chang WY. Perceptions of exercise in obese school-aged children. J Nurs Res. 2009;17(3):170-178.

8. Moore JB, Jilcott SB, Shores KA, Evenson KR, Brownson RC, Novick LF. A qualitative examination of perceived barriers and facilitators of physical activity for urban and rural youth. Health Educ Res. 2010;25(2):355-367.

9. Tergerson JL, King KA. Do perceived cues, benefits, and barriers to physical activity differ between male and female adolescents? $J$ Sch Health. 2002;72(9):374-380.

10. Zabinski MF, Saelens BE, Stein RI, Hayden-Wade HA, Wilfley DE. Overweight children's barriers to and support for physical activity. Obes Res. 2003;11(2):238-246.

11. Collins WA, Madsen SD, Susman-Stillman A. Parenting during middle childhood. In: Bornstein MH, editor. Handbook of Parenting: Volume 1, Children and Parenting, 2nd ed. London, UK: Lawrence Erlbaum Associates; 2002.

12. Child Development Institute. Parenting today: school age children development and parenting tips. 2012. Available from: http:// childdevelopmentinfo.com/child-development/piaget.shtml. Accessed October 14, 2012.

13. Cohen J. Quantitative methods in psychology: a power primer. Psychol Bull. 1992;112:155-159.

14. Kowalski KC, Crocker PR, Donen RM. The Physical Activity Questionnaire for Older Children (PAQ-C) and Adolescents (PAQA) manual, 2004. Available from: http://docsfiles.com/pdf_the physical_activity_questionnaire_for_older_children_paq_c_and.html. Accessed January 31, 2013.

15. Sanamthong B. Food Consumption and Exercise Behaviors of Obese Children Attending a Weight-control Program. Unpublished thesis. Khon Kaen, Thailand: Khon Kaen University; 2005.

16. Robbins LB, Talley HC, Wu T-Y, Wilbur J. Sixth-grade boys' perceived benefits of and barriers to physical activity and suggestions for increasing physical activity. J Sch Nurs. 2010;26(1):65-77.

17. Wannasuntad S. Factors Predicting Thai Children's Physical Activity. ProQuest: Nursing, University of California, San Francisco; 2007.

18. Protudjer JL, Marchessault G, Kozyrskyj AL, Becker AB. Children's perceptions of healthful eating and physical activity. Can J Diet Pract Res. 2010;71(1):19-23.

19. Heitzler CD, Lytle LA, Erickson DJ, Barr-Anderson D, Sirard JR, Story M. Evaluating a model of youth physical activity. Am J Health Behav. 2010;34(5):593-606.

20. Ziviani J, Macdonald D, Jenkins D, Rodger S, Batch J, Cerin E. Physical activity of young children. OTJR: Occupation Participation and Health. 2006;26(1):4-14.

21. Brockman R, Jago R, Fox KR. The contribution of active play to the physical activity of primary school children. Prev Med. 2010;51(2): 144-147.

22. Kitzman-Ulrich H, Wilson DK, Van Horn ML, Lawman HG. Relationship of body mass index and psychosocial factors on physical activity in underserved adolescent boys and girls. Health Psychol. 2010;29(5):506-513.

23. Heitzler CD. Patterns and correlates of physical activity among children and adolescents. Proquest 2009. 
24. Robbins LB, Sikorskii A, Hamel LM, Wu T-Y, Wilbur J. Gender comparisons of perceived benefits of and barriers to physical activity in middle school youth. Res Nurse Health. 2009;32(2):163-176.

25. Rodriguez NCC. An examination of behavioral, psychological, sociocultural and environmental factors that may explain gender differences in children's physical activity. ProQuest 2009.
26. Kin-Isler A, Asci FH, Altintas A, Guven-Karahan B. Physical activity levels and patterns of 11-14 year-old Turkish adolescents. Adolescence. 2009;44(176):1005-1015.

\section{Publish your work in this journal}

The Journal of Multidisciplinary Healthcare is an international, peerreviewed open-access journal that aims to represent and publish research in healthcare areas delivered by practitioners of different disciplines. This includes studies and reviews conducted by multidisciplinary teams as well as research which evaluates the results or conduct of such teams or healthcare processes in general. The journal covers a wide range of areas and welcomes submission from practitioners at all levels, from all over the world. The manuscript management system is completely online and includes a very quick and fair peer-review system. Visit http://www.dovepress.com/testimonials.php to read real quotes from published authors.

Submit your manuscript here: http://www.dovepress.com/journal-of-multidisciplinary-healthcare-journal 